\title{
A MACROSCALE MODELLING APPROACH FOR NONLINEAR ANALYSIS OF MASONRY ARCH BRIDGES
}

\author{
B. PANTO' ${ }^{1}$, C. CHISARI ${ }^{2}$, L. MACORINI ${ }^{*}$, B.A. IZZUDDIN ${ }^{1}$ \\ ${ }^{1}$ Department of Civil and Environmental Engineering, Imperial College London \\ South Kensington Campus, London SW7 2AZ, UK \\ e-mail: \{ b.panto, 1.macorini*, b.izzuddin\}@imperial.ac.uk (*corresponding author) \\ ${ }^{2}$ Department of Architecture and Industrial Design, Università della Campania "Luigi Vanvitelli" \\ via San Lorenzo - Abazia di San Lorenzo, Aversa (CE), Italy \\ e-mail: corrado.chisari@unicampania.it
}

Keywords: Nonlinear Analysis, Macromodels, Mesoscale Approach, Masonry Arch Bridges.

\begin{abstract}
Masonry arches represent the most important structural components of masonry arch bridges. Their response is strongly affected by material nonlinearity which is associated with the masonry texture. For this reason, the use of mesoscale models, where units and mortar joints are individually represented, enables accurate response predictions under different loading conditions. However, these detailed models can be very computationally demanding and unsuitable for practical assessments of large structures. In this regard, the use of macro-models, based on simplified homogenised continuum representations for masonry, can be preferable as it leads to a drastic reduction of the computational burden. On the other hand, the latter modelling approach requires accurate calibration of the model parameters to correctly allow for masonry bond. In the present paper, a simplified macro-modelling strategy, particularly suitable for nonlinear analysis of multi-ring brick-masonry arches, is proposed and validated. A numerical calibration procedure, based on genetic algorithms, is used to evaluate the macro-model parameters from the results of meso-scale "virtual" tests. The proposed macroscale description and the calibration procedure are applied to simulate the nonlinear behaviour up to collapse of two multi-ring arches previously tested in laboratory and then to predict the response of masonry arches interacting with backfill material. The numerical results confirm the ability of the proposed modelling strategy for masonry arches to predict the actual nonlinear response and complex failure mechanisms, also induced by ring separation, with a reduced computational cost compared to detailed mesoscale models.
\end{abstract}

\section{INTRODUCTION}

Old masonry arch bridges belong to the cultural and architectural heritage and still play a critical role within railway and roadway networks in Europe and worldwide. These structures were built following empirical rules and were not designed to resist current traffic loading and extreme events, such as earthquakes. An accurate assessment of the ultimate performance of these complex structural systems represents a crucial step to prevent future failures and preserve such historical masonry structures for the next generations. 
Masonry arch barrels are the key structural components of masonry arch bridges. Their nonlinear behaviour is strongly influenced by the mechanical properties of the two constituents, masonry units and mortar joints, and their arrangement to form the brickwork of the arch (i.e. masonry bond). Two main categories of masonry arch bridges can be identified: stone masonry and brick masonry bridges. In the first group, the arches are built from large voussoirs organised in a single arch ring [1] (Figure 1a). Conversely, in the case of brick masonry bridges, a multi-ring arrangement is usually utilised, where the number of rings depends on the span length of the arch. The rings are typically bonded together using the stretcher method [2] (Figure 1b), where the connection between adjoining rings is guaranteed by continuous mortar joints. Numerous laboratory and in-situ tests were performed to investigate the failure mechanisms of masonry arches and bridges, considering also the influence of backfill and spandrel walls under monotonic and cyclic loading conditions [3]. Moreover, specific studies focused on multi-ring arches pointed out the high influence of the detachment and sliding along the ring joints on the ultimate strength and failure mode of the arch [4].

In previous research, different numerical strategies have been proposed to simulate the nonlinear behaviour of masonry arches and bridge [3]. Generally, approaches based upon limit analysis principles can be effectively used to estimate the ultimate load capacity [5]. However, such strategies do not provide information about the nonlinear response before collapse, and they are often based upon crude assumptions, e.g. the representation of masonry as a no-tension material, which may lead to underestimating the ultimate resistance of
masonry arches. Previous studics comprise also simplified 2 P finite element (FE) limpt-
analysis descriptions to simulate the arch-backfill interaction [6][7] and 3D nonlinear FE
strategies with elasto-plastic solid elements [1][8][9], where masonry is assumed as a
homogeneous isotropic material disregarding its anisotropic nature. More recent numerical
models for masonry arched structures and bridges include the micro-model strategy proposed by Milani et al. [10] using triangular rigid elements and nonlinear links, the Discrete Macro-

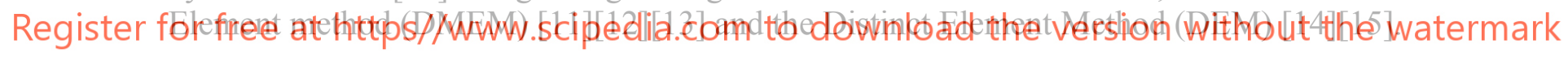
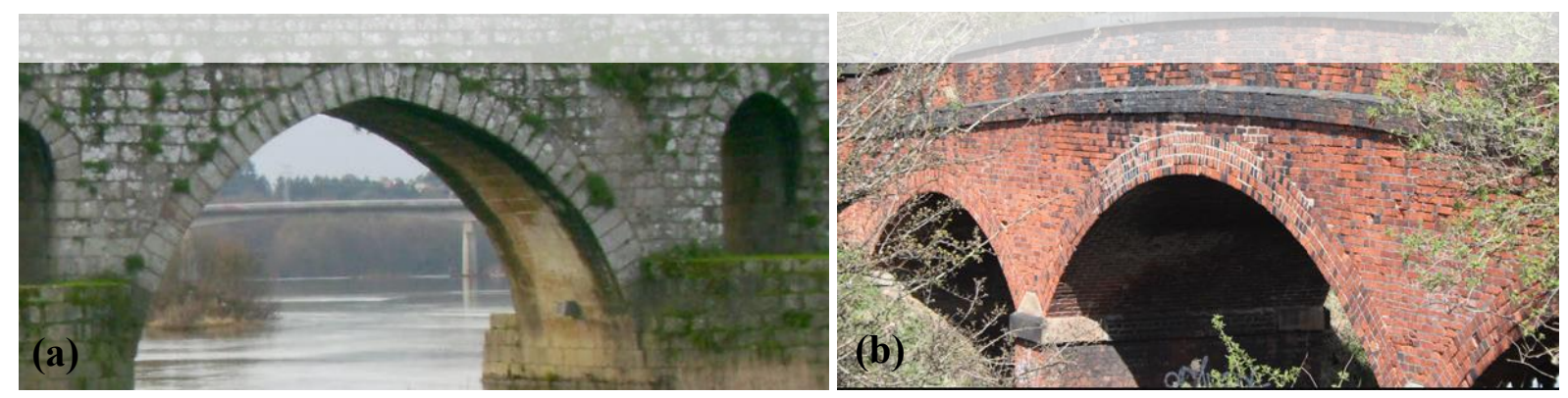

Figure 1: (a) Roman stone-bridge over the Limia river (Portugal) and (b) Brick Rail bridge, Stapleford (UK).

A detailed 3D mesoscale modelling strategy for masonry arch bridges has been previously developed at Imperial College [16][17], which is considered for the calibration of the macroscale approach proposed in the current paper. According to this strategy, the masonry parts of the bridge are simulated by using linear solid elements and $2 \mathrm{D}$ nonlinear interface elements to explicitly allow for the masonry bond [18]. The backfill is modelled by elastoplastic solid elements, and the connection between the masonry components and the backfill 
is modelled through nonlinear interfaces representing the actual frictional interaction. This approach generally leads to accurate response predictions, including under extreme loading, but it is associated with significant computational cost which may prevent its use in the practical assessment of real large structures.

This paper proposes a more efficient macroscale strategy for masonry arches and bridges. Elasto-plastic 3D continuum elements interacting with 2D nonlinear interfaces are employed to model a masonry arch but, as opposed to the mesoscale strategy, the mesh characteristics do not depend on the size of the masonry units as the masonry bond is not explicitly represented. The damage-plasticity model proposed in [19] and a multi-surface frictional model [20] are employed for solid and interface elements. The mechanical parameters of the two models are evaluated by solving a multi-object optimization problem by means of a genetic algorithm [21], considering mesoscale predictions of virtual numerical experiments on small masonry components. The model is validated based on the response of two multi-ring masonry arches also interacting with backfill.

\section{PROPOSED MACRO-MODEL}

In the proposed FE modelling strategy, the arch is discretised by a regular mesh of nonlinear 20-noded 3D solid continuum elements. In addition, 2D nonlinear zero-thickness interface elements are arranged along the circumferential mid-thickness surface of the arch to simulate damage associated with potential ring separation (Figure 2), where each interface lumps the linear deformability forming the physical elements are not dirce elements can be employed along the length response detail, but at least two solid element s.t. arch to accommodate
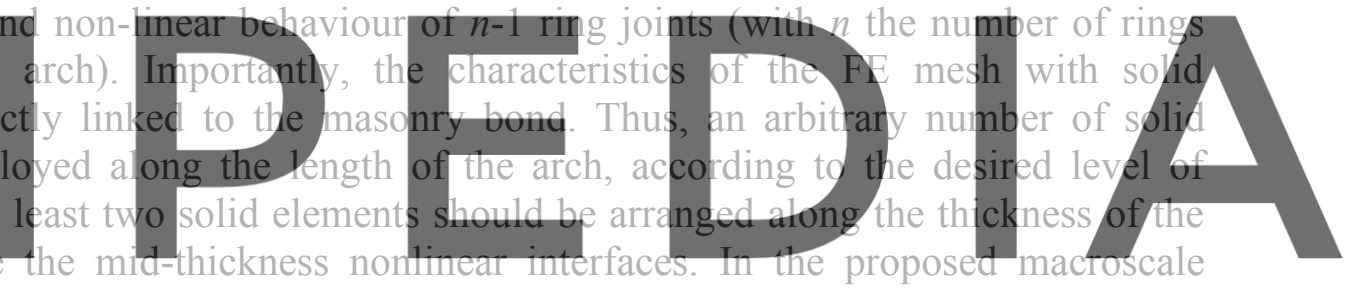
representation implemented in ADAPTIC [23], the isotropic plastic-damage material model

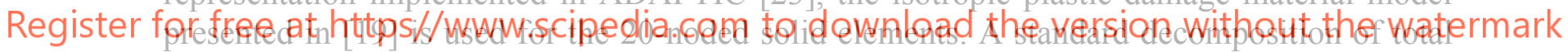

strains $(\varepsilon)$ in elastic $\left(\varepsilon_{e}\right)$ and plastic $\left(\varepsilon_{p}\right)$ components is considered, and the stress tensor $(\sigma)$ is obtained from the effective stress tensor $(\overline{\boldsymbol{\sigma}})$ and a scalar damage variable $d(\overline{\boldsymbol{\sigma}}, \kappa t, \kappa c)$. The latter variable depends on the stress state and two historical variables $(\kappa t, \kappa c)$ representing the evolution of plastic strains in tension and in compression.

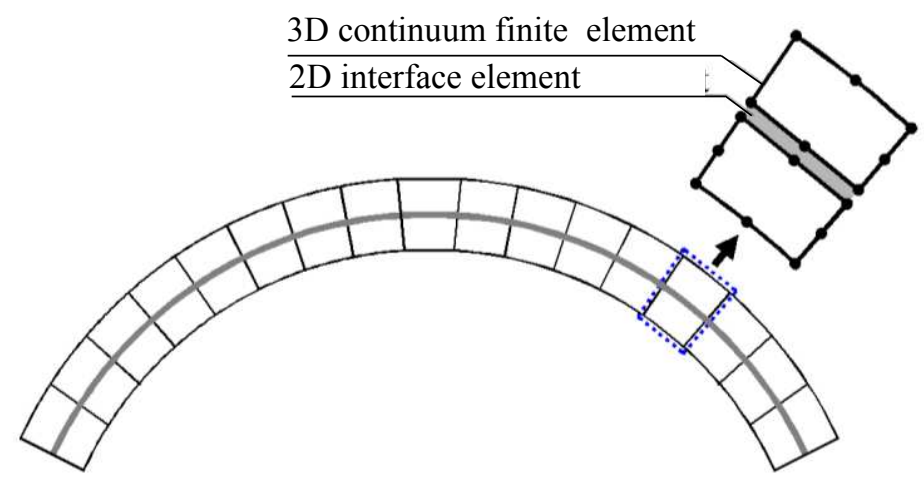

Figure 2: Illustrative FE mesh for proposed macroscale description with solid elements and nonlinear interfaces. 
The material relationship is expressed analytically by: $\boldsymbol{\sigma}=(1-d) \overline{\boldsymbol{\sigma}}=(1-d) \boldsymbol{K}_{\mathbf{0}}\left(\boldsymbol{\varepsilon}-\boldsymbol{\varepsilon}_{\boldsymbol{p}}\right)$ where, $\boldsymbol{K}_{\mathbf{0}}$ is the fourth-order isotropic elastic tensor. The local hardening plastic problem is solved at each integration point to evaluate the effective stress, adopting a non-associated elasto-plastic constitutive law with Drucker-Prager-like plastic flow potential.

2D 16-noded interface elements [18] are employed for the mid-thickness circumferential interfaces, using the plasticity-damage constitutive model proposed in [20]. According to this model, the stress and strain fields are composed of a normal component in the direction orthogonal to the interface and two tangential components on the plane of the interface. The effective stresses are evaluated at each Gauss point by solving a linear hardening elastoplastic problem considering three-surface plastic yield domain to simulate the tensile, sliding and compressive failures. Then, the nominal stresses are obtained by multiplying the effective stresses with damage matrix $\mathbf{D}$, containing the damage index in traction, shear and compression ranging from 0 (no-damage) to 1 (complete damage).

\subsection{Model calibration}

The mechanical calibration of the proposed model requires the determination of several material parameters defining the linear and nonlinear behaviour of the solid elements and the 2D interfaces, as described in [19] and [20]. For this reason, an objective and robust calibration procedure represents a fundamental step to guarantee the model accuracy and applicability. In this study, the unknown model parameters are evaluated by enforcing an (Figure 3a), subjected to specific boundary/loading conditions equivalent representation by the proposed macroscale optimisation problem (where $m$ is the number based on Non-Dominated Sorting Genetic Alg [22] to minimise the discrepancy between the virtual test and

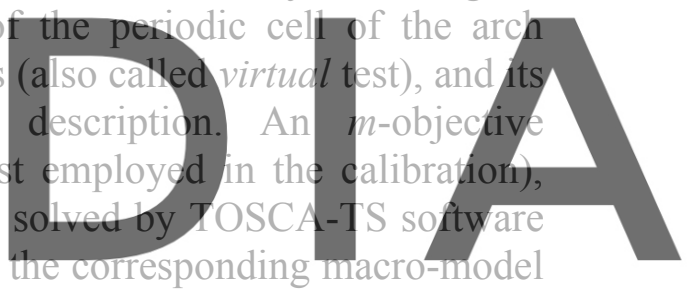
responses in terms of global strain energy.

Register for free at https//WwW.scipedia.com to download the version without the watermark
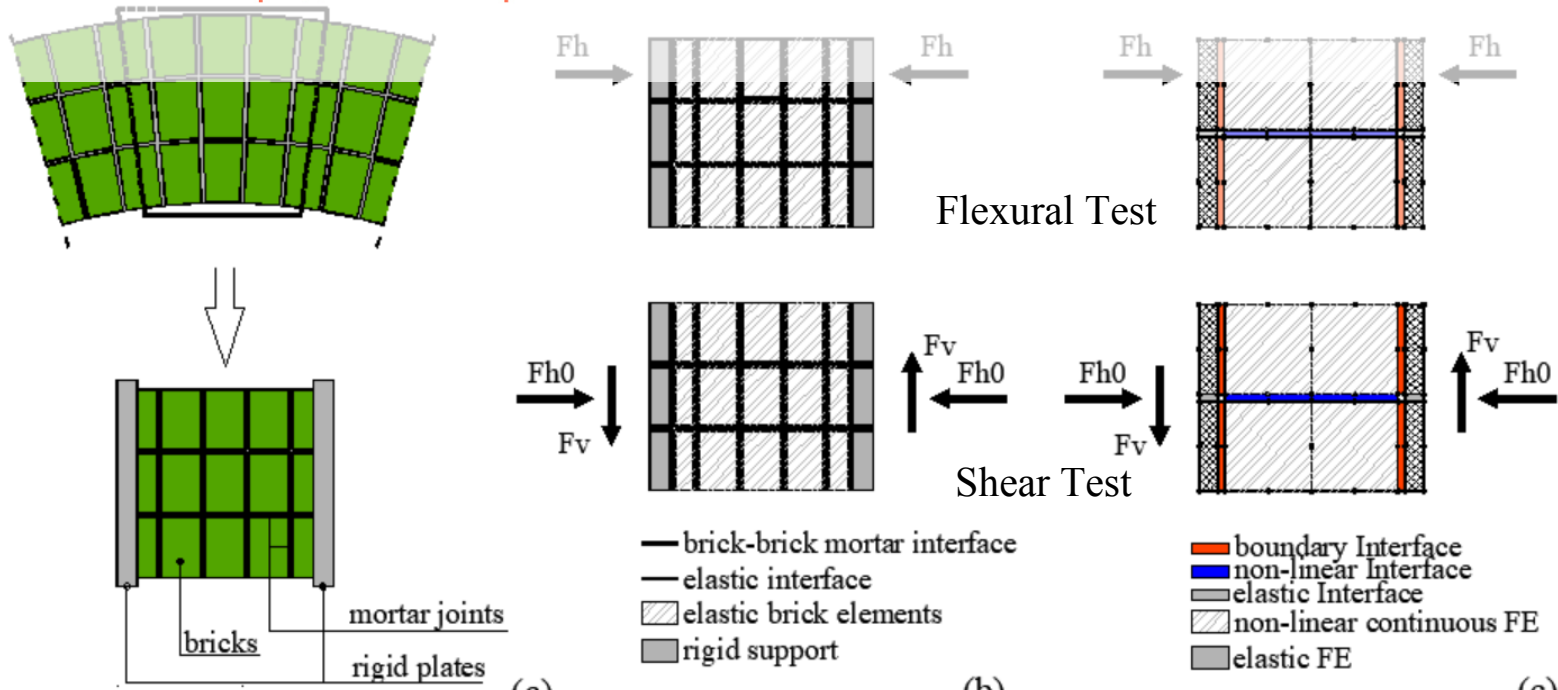

(a)

Figure 3: Calibration procedure: (a) elementary cell; (b) mesoscale virtual test; and (c) equivalent macromodel. 
In the following, two virtual tests are considered: $i$ ) a flexural test, in which an eccentric axial force $\left(F_{h}\right)$ is applied with increasing amplitude; $\left.i i\right)$ a shear test, where an increasing shear force $\left(F_{v}\right)$ is applied after an initial axial force $\left(F_{h 0}\right)$ which is maintained constant during the analyses. In both tests, two rigid plates are modelled to transfer the loads uniformly to the masonry specimens. One plate is fully restrained while the other is free in the flexural test and restrained against rotation in the shear test. The plates are connected to the masonry by elastic interfaces with high normal and shear stiffness, in the case of the shear test, and with high normal stiffness and low shear stiffness, in the case of the flexural test. Illustrations of the mesoscale (virtual test) and the equivalent macromodel descriptions are shown in Figure $3 \mathrm{~b}$ and Figure 3c.

\section{NUMERICAL APPLICATIONS}

In this section, the proposed macromodel and the calibration procedure presented in Section 2 are applied to simulate the response of two brick-masonry arches with stretcher bond tested by Melbourne et al. [24], namely Arch G and Arch T specimens. Arch G is a two-ring arch with $3 \mathrm{~m}$ span, $215 \mathrm{~mm}$ thickness, $455 \mathrm{~mm}$ width and strong bricks. Arch $\mathrm{T}$ is characterised by three rings, $5 \mathrm{~m}$ span, $1250 \mathrm{~mm}$ rise, $330 \mathrm{~mm}$ thickness, $675 \mathrm{~mm}$ width and weak bricks. Two initial vertical forces, equal to $10 \mathrm{kN}$ for Arch $\mathrm{G}$ and $22.5 \mathrm{kN}$ for Arch T, were applied at the quarter and three-quarter span and kept constant during the test. Subsequently, a vertical force at quarter span was increased up to collapse under force control.
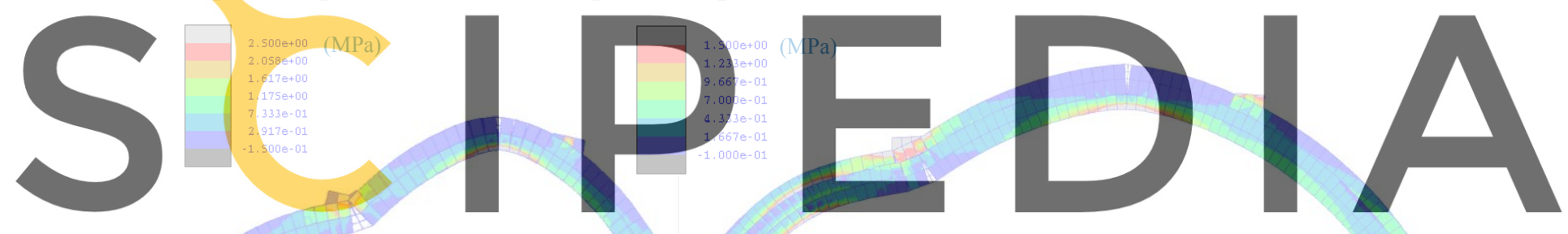

Register for free at https//wwww.scipedia.com to download the version without the watermark Figure 4: Final deformed shapes with Von-Mises stress of (a) Arch G, and (b) and Arch T.

The responses at failure of the two arches were different. While Arch G experienced a typical 4-hinge mechanism due to the formation of four large radial cracks, Arch T showed a more complex ultimate response characterised also by sliding separation between adjacent rings.

The two arches have been simulated using the detailed mesoscale model and the proposed calibrated macroscale description. As the available experimental material data are not sufficient to fully characterise the mesoscale model, the unknown mesoscale mechanical properties have been evaluated according to [16] to fit the experimental results. The complete set of parameters, adopted in the analyses, are reported in Table 1, where $E_{b}$ and $v$ are Young's modulus and Poisson's ratio of the bricks; $k_{n}$ and $k_{t}$ are the normal and tangential stiffness of the interfaces; $f_{t}, f_{t}$ and $c$ are the tensile, compressive strengths and cohesion of the interfaces; $G_{t}, G_{s}, G_{c}$ are the fracture energies in traction, compression and sliding; $\operatorname{tg} \phi$ and $\operatorname{tg} \phi_{b}$ are the factors governing the yield-surface and plastic potential functions. Figure 4 shows the deformed shapes at failure obtained by the mesoscale models for the two arches with the Von-Mises stress. The numerical failure modes are in good agreement with those observed during the experiments [24]. 


\subsection{Arch G}

The material parameters of the 3D continuum model for solid elements (Table 2) used in the proposed macroscale approach have been calibrated applying the procedure described in Section 2, adopting for the interface elements the parameters used in the mesoscale counterpart for the masonry joints (Table 1). The latter assumption is justified by the fact that in Arch $G$ the interfaces coincide with the actual ring-to-ring mortar joints. The loadingdisplacement curves of the meso- and macromodel are compared in Figures $5 \mathrm{a}$ and $5 \mathrm{~b}$ for the flexural and shear tests, respectively. The curves are expressed in terms of relative displacement of the plates versus the applied shear force for the shear test, and in terms of relative rotation versus the external moment for the flexural test. Figure 6 shows the final damage patterns in the interface elements of the mesoscale model (e.g. tension damage and sliding damage for the flexural and shear test, respectively) and in the solid elements of the macro-model (e.g. global damage). The load-displacement curves for Arch G are provided in Figure 7, where the results obtained by the detailed mesoscale and the proposed macroscale models are compared against the experimental data. The curves are expressed in terms of vertical (Figure 7a) and horizontal (Figure 7b) displacements at the quarter span versus the applied vertical load (F). A satisfactory agreement can be observed between the macro-model and the meso-scale response, which is very close to the experimental curve both in terms of initial stiffness and nonlinear response up to collapse.
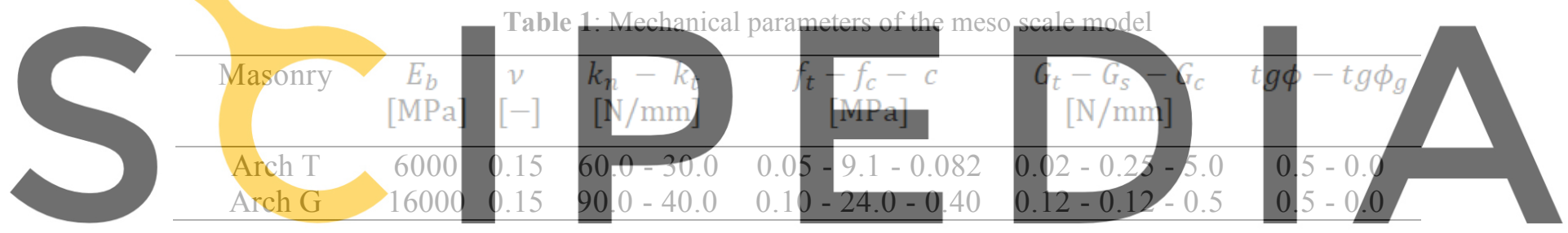

Table 2: Mechanical parameters of the 3D plasticity-damage model adopted in the tanalyses of Arch G

Register for free at https//wWw.scipedia,com to download the version without the watermark

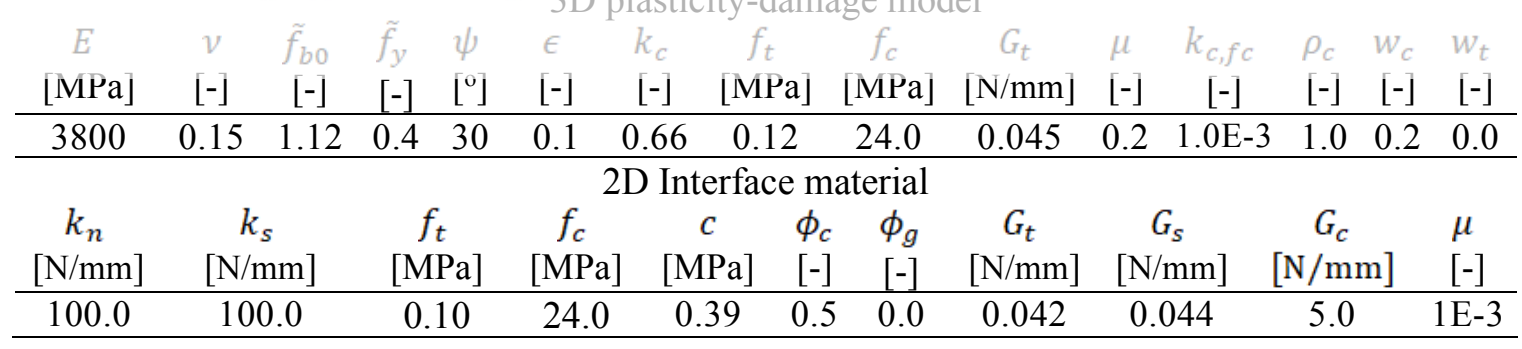

Table 3: Mechanical parameters adopted in the analyses of Arch T

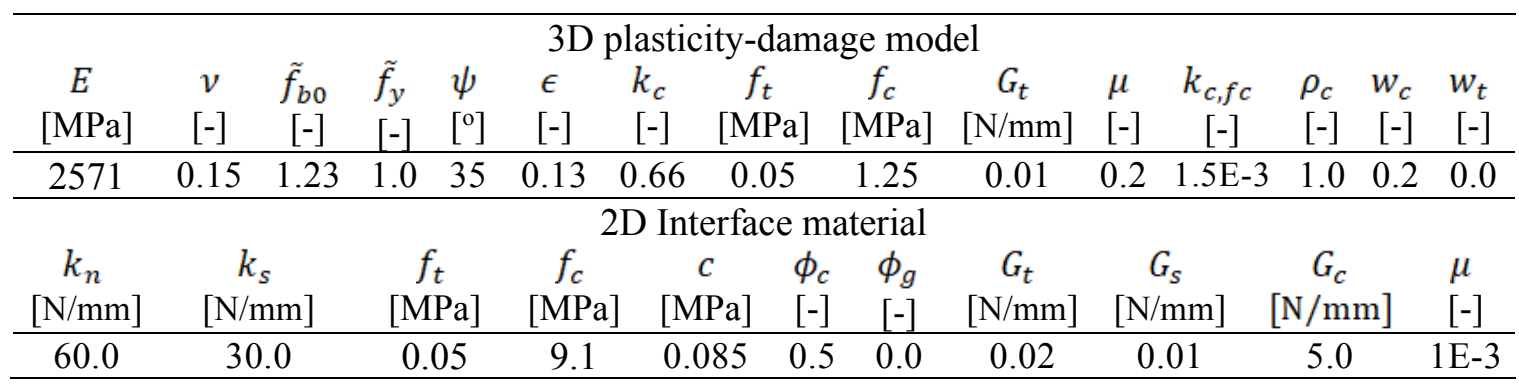


However, the macro-model overestimates the peak-load by $20 \%$ approximately. The ultimate deformed shape of the macro-model with the Von-Mises stress and the damage index, are shown respectively in Figure $8 \mathrm{a}$ and Figure $8 \mathrm{~b}$. Both the stress and damage patterns predicted by the macro-model are compatible with the meso-scale prediction (Figure 4a), confirming the ability of the macromodel to predict the main features of the arch response up to failure.

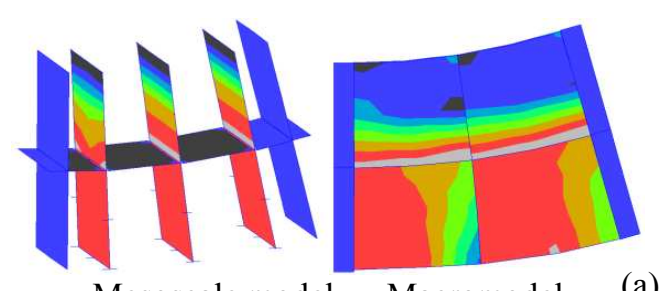

Mesoscale model Macromodel

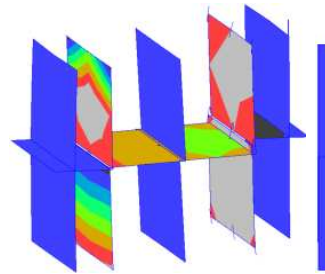

Mesoscale mode

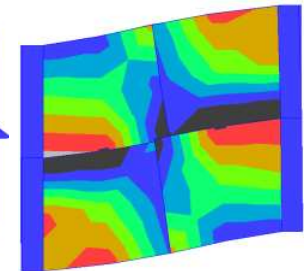

(b)

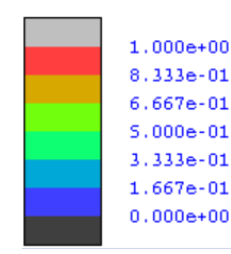

Figure 5: Damage pattern at the last step of the analysis of the flexural (a) and shear (b) virtual test.
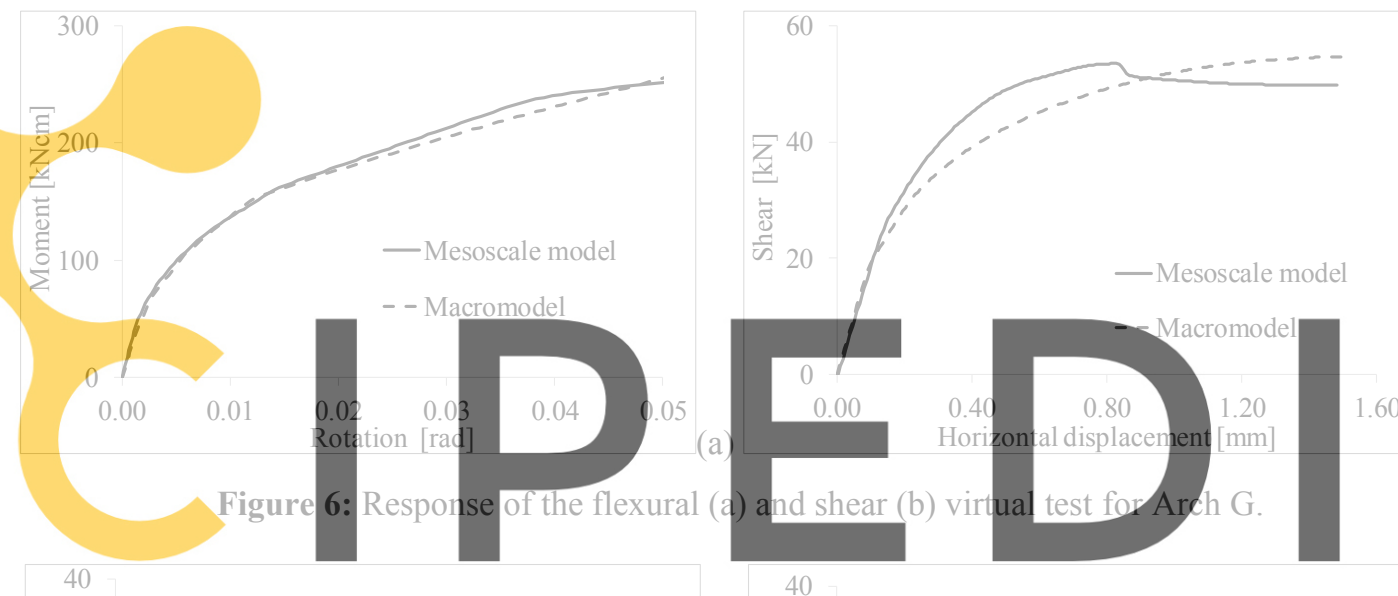

40

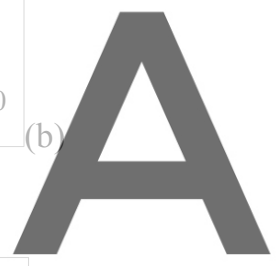

Register for free at https//wywn.Scipedia.com to
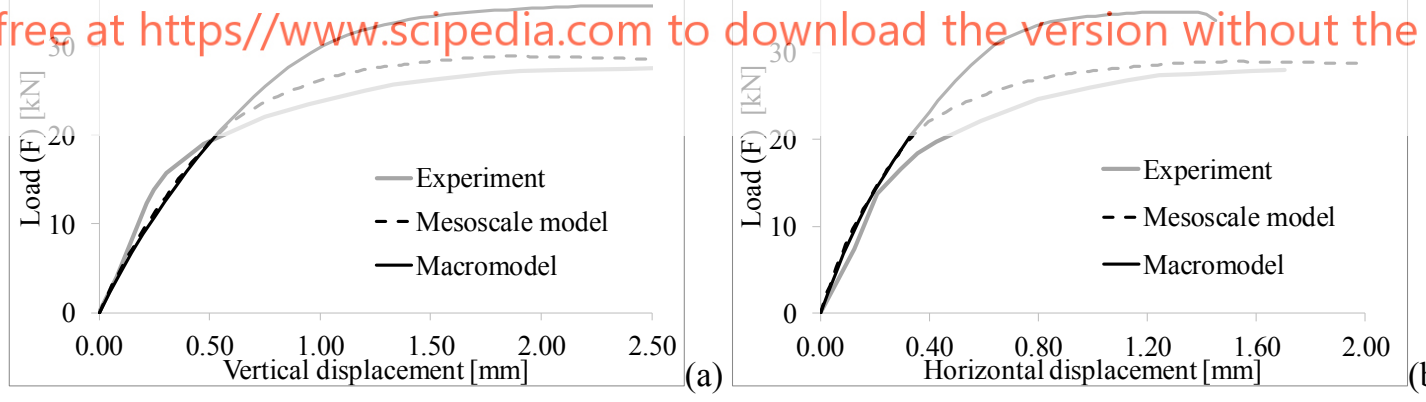

Figure 7: Capacity curves of Arch G: vertical (a) and horizontal (b) displacement at the left patch load.
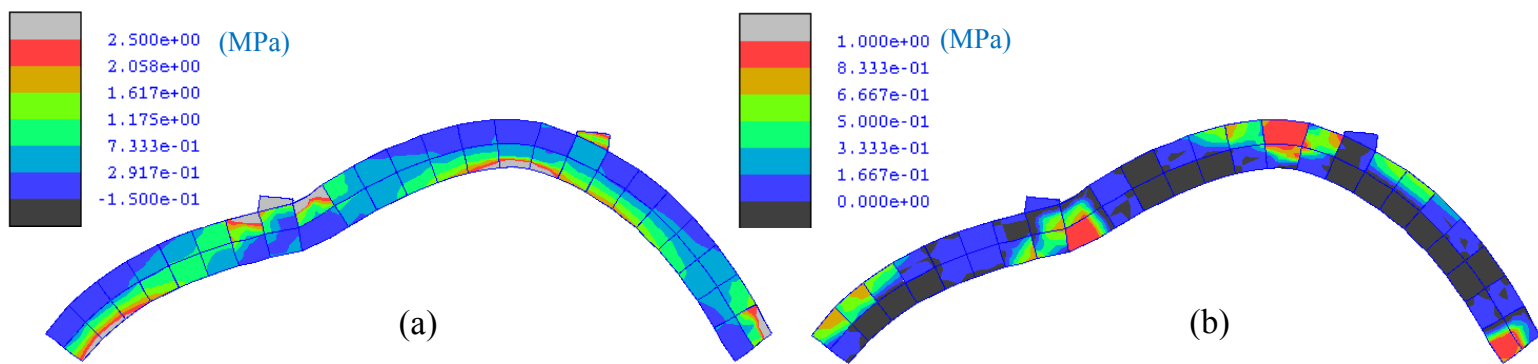

Figure 8: Failure mechanism of Arch G obtained by the macro-model: (a) Von-Mises stress, and (b) damage. 


\subsection{Arch T}

This section reports the results of the numerical simulations performed on the three-ring Arch T, whose collapse behavior is characterized by significant sliding between the rings. The same procedure followed for the two-ring arch in Section 3.1 is applied to estimate both the parameters for the triaxial constitutive law of the 3D continuum elements and for the nonlinear plastic-damage model used for the nonlinear interfaces. The resulting set of macromodel parameters is reported in Table 3. The deformed shapes and load-displacement curves for the flexural and shear virtual tests are reported in Figure 9 and Figure 10. It can be observed that the calibrated macromodel fits well the mesoscale response with a high level of accuracy, both in terms of nonlinear response and damage pattern. The load displacement curves for Arch T are shown in Figure 11. As in the previous example, the numerical curves obtained using the calibrated macromodel are compared against the mesoscale predictions and the experimental results. In this case, the macroscale model slightly overestimates the elastic stiffness of the arch, but it provides a good prediction of the ultimate load capacity.

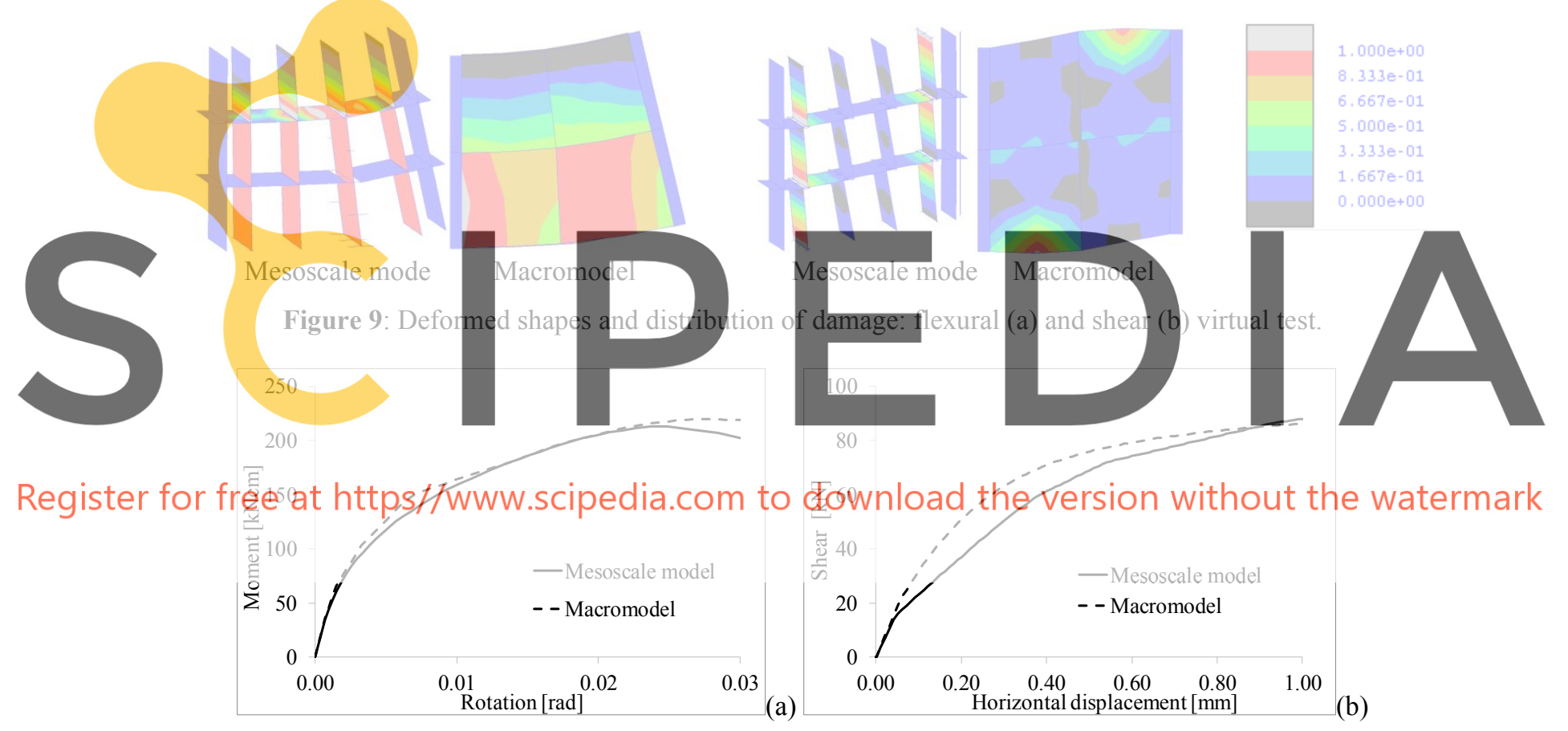

Figure 10: Response of the flexural (a) and shear (b) virtual test for Arch T.
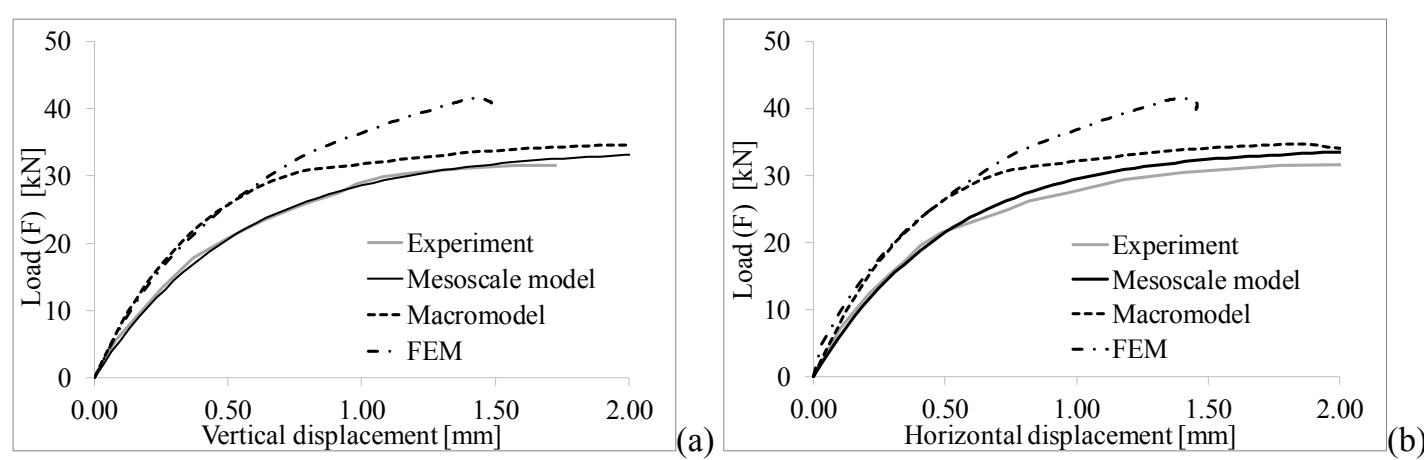

Figure 11: Capacity curves of the Arch T: vertical (a) and horizontal (b) displacement at the left patch load. 


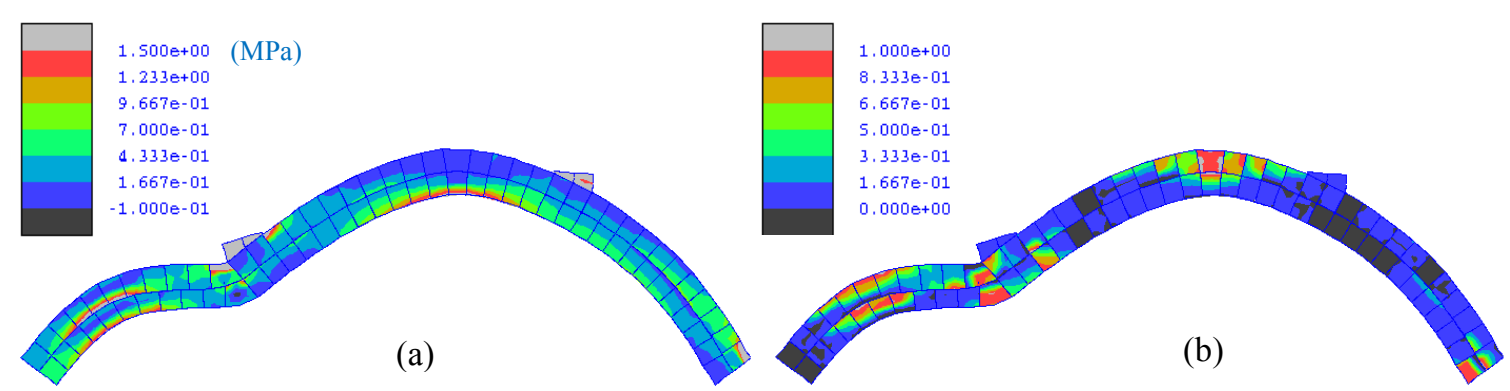

Figure 12: Failure mechanism of Arch T obtained by the macro-model: (a) Von-Mises stress, and (b) damage.

The failure mechanism is depicted in Figure 12, correlated with the Von-Mises stress (Figure 12a) and damage (Figure 12b) patterns. The activation of two plastic hinges can be observed, which are located approximately at the three quarter span and at the right skewback. Large sliding between the rings is also observed between the section where the load is applied and the left skewback. The latter results are substantially consistent to what is predicted by the mesoscale model and observed in the physical tests [24].

To investigate the role played by the nonlinear interfaces within the macromodel, additional simulations have been conducted using a full 3D continuum model (FEM), which does not utilise 2D interface elements, with the calibrated material parameters in Table 3, where the results are shown in Figure 11. It can be observed, that for small displacements (up to $0.05 \mathrm{~mm}$ vertical and horizontal displacements) the FEM model and the proposed macromodel show the same response. After this point, the two responses diverge due to the sliding activation in the mid-thickness interfaces The FFM model overestimates the ultimate strength
of the arch with an ultimate load prediction $20 \%$ higher than the proposed macromodel and
$25 \%$ higher than the detailed mesoseale model, which provides a very close estimate of the
ultimate load capacity to the value measured in the test.

4 ARCH-BACKINFILL INTERACTION

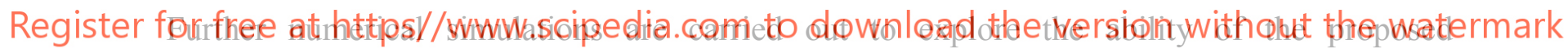
macroscale modelling strategy to predict the behaviour of masonry arches interacting with backfill, as in real masonry bridges. The arch specimens, Arch G and Arch T, are analysed connecting the extrados of the two arches to a backfill domain.

In the models for the two specimens with backfill, the backfill with density $22 \mathrm{kN} / \mathrm{m}^{3}$ extends horizontally $2460 \mathrm{~mm}$ from the two supports of the arches and $300 \mathrm{~mm}$ vertically above the crown. The strip model is $2880 \mathrm{~mm}$ wide. A uniform vertical line load is applied at the top surface of the backfill at the three-quarter arch span. Full support is assumed at the base of the arch and the backfill and on the two vertical sides of the backfill. Moreover, the horizontal displacements on the two lateral faces of the arch and backfill are restrained to represent a plane strain condition. The backfill is modelled using a FE discretization with 15-noded tetrahedral elements. According to [17], an elasto-plastic material model with a modified Drucker-Prager yield criterion is employed assuming Young's modulus $E_{b}=500 \mathrm{MPa}$, cohesion $c_{b}=0.001 \mathrm{MPa}$, friction and dilatancy coefficients $\operatorname{tg} \phi_{b}=0.95$ and $\operatorname{tg} \psi_{b}=0.45$. The interaction between the arch and the backfill is simulated by introducing nonlinear interfaces at the extrados with tensile strength $f_{f i}=0.002 \mathrm{MPa}$, cohesion $c_{i}=0.0029 \mathrm{MPa}$, friction coefficient $\operatorname{tg} \phi_{i}=0.6$ and zero dilatancy. 
The load-displacement curves obtained using mesoscale and macroscale models are shown in Figure 13. A very good agreement up to collapse can be observed. Similar failure mechanisms are predicted by the two modelling strategies as shown by the ultimate deformed shapes and damage contours in Figures 14, 15 and 16. It should be noted that the masonry material properties for the macroscale models have been calibrated based on the virtual tests for the two arches (Tables 1,2 and 3). The results obtained confirm the potential of the proposed modelling strategy with calibrated macroelements in providing accurate predictions of the response of masonry arches and bridges.
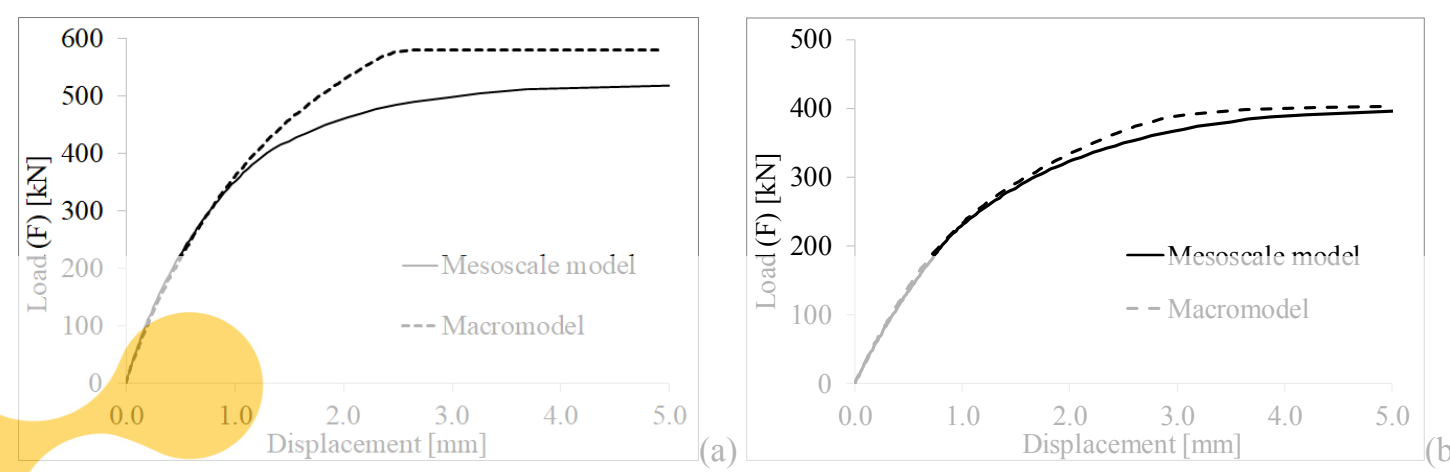

Figure 13: Capacity curves of the arches with backfill: (a) Arch G, and (b) Arch T.
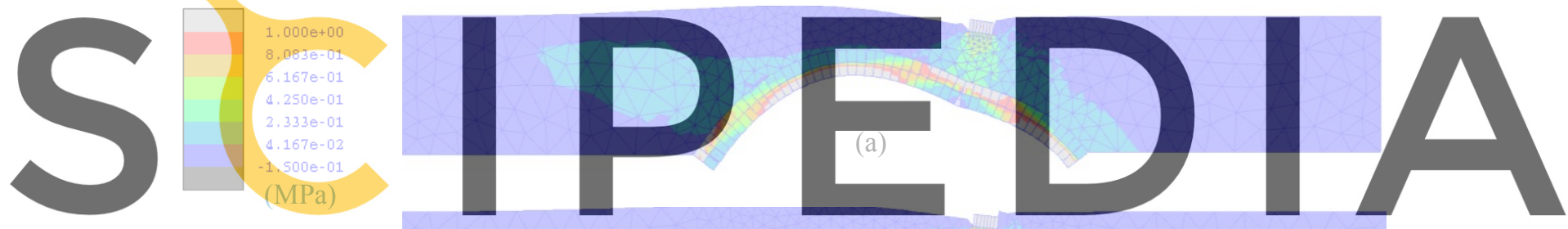

Register for free at https//www.scipedia.com to download the version without the watermark

(b)

Figure 14: Failure mode and Von-Mises stress of Arch G with backfill: (a) mesoscale model; (b) macromodel.

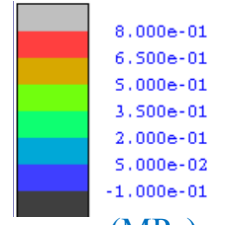

$(\mathrm{MPa})$
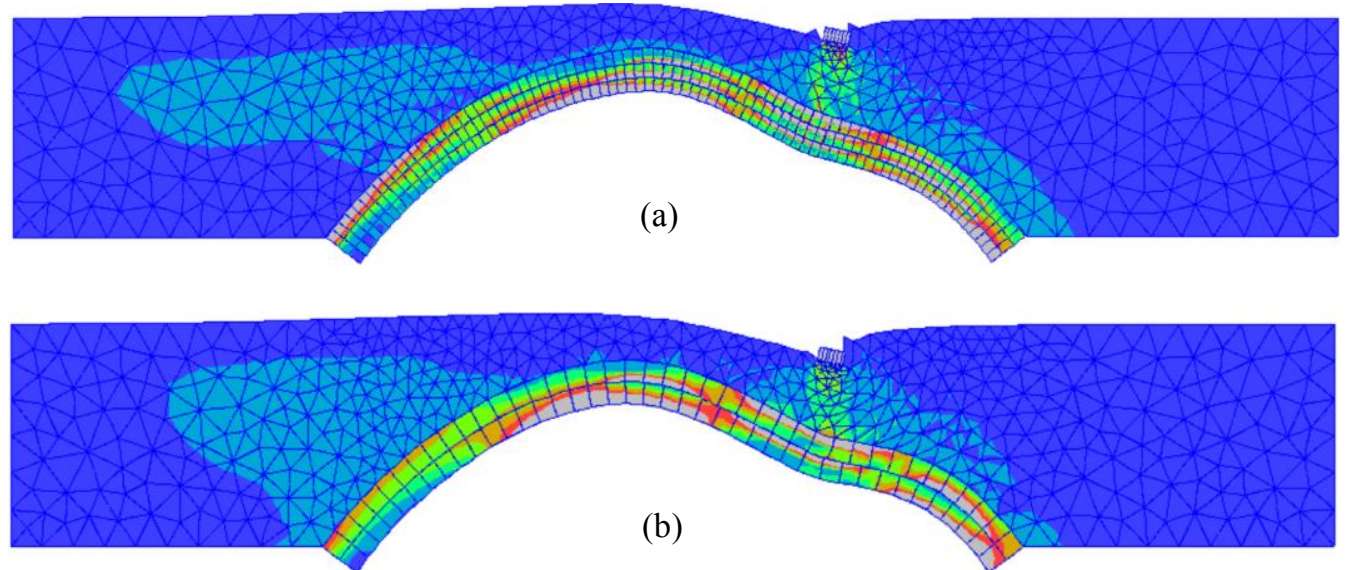

Figure 15: Failure mode and Von-Mises stress of Arch T with backfill: (a) mesoscale model; (b) macromodel. 


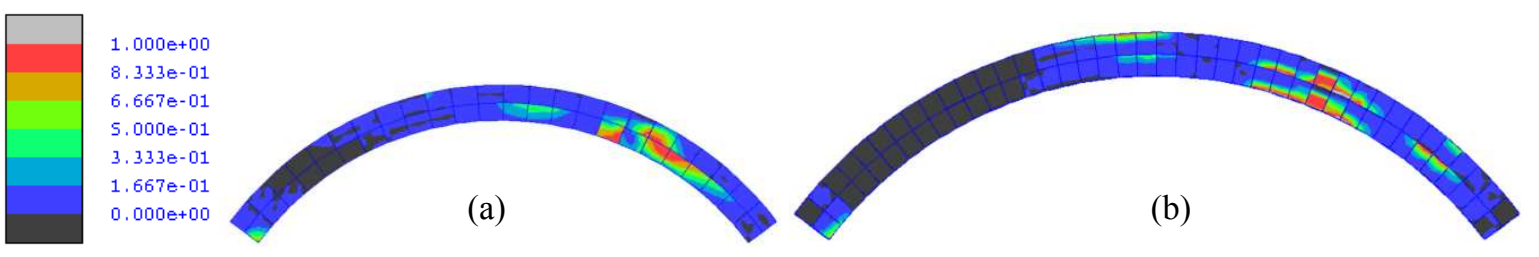

Figure 16: Macro-model damage in (a) Arch G, and (b) Arch T.

\section{CONCLUSIONS}

In this study a macro-modelling strategy for brick-masonry multi-ring arches is proposed. This modelling approach benefits from enhanced efficiency compared to detailed mesoscale descriptions, since the adopted FE mesh is independent of the actual masonry bond. A hybrid strategy is followed in which the arch is modelled by 3D elasto-plastic continuum solid elements and 2D zero-thickness nonlinear interfaces arranged along the mid-thickness circumferential surface to simulate potential ring separation. An effective and robust procedure based on genetic algorithms is established to calibrate the macromodel mechanical parameters considering results from mesoscale simulations on virtual experiments. The accuracy and potential of the proposed approach is demonstrated in two numerical examples, based on masonry arches tested in previous research, which are characterised by different failure mechanisms. The results show a very good agreement between the calibrated macromodels and detailed mesoscale descriptions, including arches interacting with backfill as in real masonry bridges, thus demonstrating the potential of the proposed calibrated macromodelling approach in the practical assessment of masonry arch bridges.

Acknowledgements. This work was supported by the European Commission through the Marie Skłodowska-Curie Individual Fellowship IF ("RAMBEA”, Grant Agreement 846061).

\section{REFERENCES}

[1] Fanning, P. J., Boothby, T. E., and Roberts, B. J. Longitudinal and transverse effects in masonry arch assessment. Constr. Build. Mat. (2001) 15(1):51-60.

[2] Moreira, V. N., Fernandes, J., Matos, J. C., Oliveira, D.V. Reliability-based assessment of existing masonry arch railway bridges. Constr. Build. Mat. (2016) 115, 544-554.

[3] Sarhosis, V., De Santis, S., and De Felice, G. A review of experimental investigations and assessment methods for masonry arch bridges. Structure and Infrastructure Engineering (2016) 12(11):1439-1464.

[4] Melbourne, C. and Gilbert, M. 1995. The behaviour of multi-ring brickwork arch bridges. Structural Engineer (1995) 73(3):39-47.

[5] Gilbert, M., Casapulla, C., and Ahmed, H.M. 2006. Limit analysis of masonry block structures with non-associative frictional joints using linear programming. Computers and Structures (2006) 84:873-887.

[6] Cavicchi, A., and Gambarotta, L. Collapse analysis of masonry bridges taking into account arch-fill interaction. Engineering Structures, (2005) 27(4):605-615.

[7] Smith, C., and Gilbert, M. Application of discontinuity layout optimization to plane plasticity problems. Proceedings of the Royal Society A: Mathematical, Physical and Engineering Sciences (2007) 463(2086):2461-2484. 
[8] Conde, B., Ramos, L. F., Oliveira, D. V., Riveiro, B., and Solla, M. (2017). Structural assessment of masonry arch bridges by combination of non-destructive testing techniques and three-dimensional numerical modelling: Application to Vilanova bridge. Engineering Structures (2017) 148:621-638.

[9] Pelà, L., Aprile, A., and Benedetti, A. Comparison of seismic assessment procedures for masonry arch bridges. Construction and Building Materials, (2013) 38:381-394.

[10] Milani, G., and Lourenço, P. B. 3D non-linear behavior of masonry arch bridges. Computers \& Structures (2012) 110:133-150.

[11] Caddemi, S., Caliò, I., Cannizzaro, F., D’Urso, D., Occhipinti, G., Pantò, B., ... and Zurlo, R. A 'Parsimonious' 3D Discrete Macro-Element method for masonry arch bridges. Proceeding of 10th IMC Conference, Milan (Italy), 9-11 July (2018)

[12] Cannizzaro, F., Pantò, B., Caddemi, S., and Caliò, I. A Discrete Macro-Element Method (DMEM) for the nonlinear structural assessment of masonry arches. Engineering Structures (2018) 168:243-256.

[13] Pantò, B., Cannizzaro, F., Caddemi, S., Caliò, I., Chácara, C., and Lourenço, P.B. Nonlinear modelling of curved masonry structures after seismic retrofit through FRP reinforcing. Buildings (2017) 7(3), 79.

[14] Pulatsu, B., Erdogmus, E., and Lourenço, P. B. Comparison of in-plane and out-of-plane failure modes of masonry arch bridges using discontinuum analysis. Engineering Structures, (2019) 178:24-36.

[15] Sarhosis, V., Forgács, T., Lemos, J.V. A discrete approach for modelling backfill material in masonry arch bridges. Computers \& Structures (2019) 224,106108.

[16] Zhang, Y., Macorini, L. and Izzuddin, B. A. Mesoscale partitioned analysis of brickmasonry arches. Engineering Structures (2016) 124:142-166.

[17] Tubaldi, E., Macorini, L. and Izzuddin, B. A. Three-dimensional mesoscale modelling of multi-span masonry arch bridges subjected to scour. Eng.Struct. (2018) 165: 486-500.

[18] Macorini, L. and Izzuddin, B. A. A non-linear interface element for 3D mesoscale analysis of brick-masonry structures. International Journal for numerical methods in Engineering, (2011) 85(12):1584-1608.

[19] Chisari C, Macorini L, Izzuddin BA, 2020. Multiscale model calibration by inverse analysis for nonlinear simulation of masonry structures under earthquake loading. International Journal for Multiscale Computational Engineering, DOI: 10.1615/IntJMultCompEng.2020031740.

[20] Minga, E., Macorini, L. and Izzuddin, B. A. A 3D mesoscale damage-plasticity approach for masonry structures under cyclic loading. Meccanica (2018) 53(7):1591-611.

[21] Deb, K., Pratap, A., Agarwal, S. and Meyarivan, T., A Fast and Elitist Multiobjective Genetic Algorithm: NSGA-II. IEEE Trans. on Evolut. Comput. (2002) 6(2):182-197

[22] Chisari, C., Amadio, C., TOSCA: a Tool for Optimisation in Structural and Civil engineering Analyses. Int. Journal of Advanced Structural Eng. (2018) 10(4):401-419.

[23] Izzuddin, B. A., Nonlinear dynamic analysis of framed structures, $\mathrm{PhD}$, Imperial College London, 1991.

[24] Melbourne, C., Wang, J., Tomor, A., Holm, G., Smith, M., Bengtsson, P. E., Bien, J., Kaminski, T., Rawa, P., Casas, J. R., Roca, P. \& Molins, C. (2007) Masonry Arch Bridges Background document D4.7. Sustainable Bridges. Report number: Deliverable D4.7. 